\title{
STRATEGI KEWIRAUSAHAAN DAN DIGITAL MARKETING PRODUK TEH BINAHONG DI TAWANG, TASIKMALAYA, JAWA BARAT
}

\author{
Rani Rubiyanti ${ }^{1 *}$, Tovani Sri ${ }^{1}$, Adi Wibowo ${ }^{1}$ \\ ${ }^{1}$ Program Studi Diploma III, Jurusan Farmasi, Poltekkes Kemenkes Tasikmalaya, \\ * rani.rubiyanti@yahoo.co.id
}

\begin{abstract}
Entrepreneurship is a process of caressing a new business, organizing resources such as; human resources (work), natural resources (raw materials) needed for economic value-added activities that will produce, both goods and services taking into account the risks involved. Digital marketing is a term that tries to describe integrated marketing services that are used to attract attention, as well as online consumer engagement. The purpose of the community service program (PKM) is to develop a previous program where there has been no delivery of knowledge about entrepreneurship and marketing strategies with digital marketing techniques so that the community can be selfemployed and market binahong tea products to the wider community. The main target of the PKM program is the residents of Lengkongsari Subdistrict, Tawang Subdistrict, Tasikmalaya City who received the Family Hope Program (PKH) assistance which is economically unproductive. The method used includes lectures, hands-on practice, and discussion. The results of the activities concluded that: 1) Participants' knowledge about entrepreneurial strategies and digital marketing increased; 2) The community can make and package binahong tea; and 3) This activity has benefited the people of Sidorejo, especially PKK women with the increasing desire of participants to sell the Binahong products on one digital marketing account.
\end{abstract}

Keywords : Binahong tea, Digital Marketing, Entrepeneurship, Lengkongsari

\begin{abstract}
ABSTRAK
Kewirausahaan adalah suatu proses membelai bisnis baru, mengorganisasikan sumberdayasumberdaya seperti; sumberdaya manusia (tenga kerja), sumberdaya alam (bahan baku) yang diperlukan untuk kegiatan pemberian nilai tambah ekonomis yang akan menghasilkan produk, baik barang maupun jasa dengan mempertimbangkan risiko yang terkait. Secara sederhana digital marketing adalah terminologi yang mencoba mendeskripsikan jasa pemasaran terintegrasi yang digunakan untuk menarik perhatian, serta pelibatan konsumen secara online. Tujuan dari program pengabdian kepada masyarakat (PKM) ini adalah mengembangkan program sebelumnya dimana belum ada penyampaian ilmu tentang strategi kewirausahaan dan pemasaran dengan teknik digital marketing agar masyarakat dapat berwirausaha dan memasarkan produk teh binahong ke masyarakat luas. Sasaran utama program PKM ini adalah warga Kelurahan Lengkongsari Kecamatan Tawang Kota Tasikmalaya yang mendapat bantuan Program Keluarga Harapan (PKH) 21 | Edukasi Masyarakat Sehat Sejahtera (EMaSS) : Jurnal Pengabdian kepada Masyarakat Volume 2 No.1 Tahun 2020
\end{abstract}


yang merupakan masyarakat tidak produktif secara ekonomis. Metode yang digunakan meliputi ceramah, praktik langsung, dan diskusi. Hasil kegiatan memyimpulkan bahwa: 1) Pengetahuan peserta tentang strategi kewirausahaan dan digital marketing meningkat; 2) Masyarakat dapat membuat dan mengemas teh binahong; dan 3) Kegiatan ini telah memberi manfaat bagi masyarakat Sidorejo, khususnya ibu-ibu PKK dengan meningkatnya keinginan peserta menjual produk the binahong pada salah satu akun digital marketing.

Kata Kunci: kewirausahaan, digital marketing, teh binahong, lengkongsari

\section{PENDAHULUAN}

Kota Tasikmalaya menjadi daerah otonom terpisah dari Kabupaten Tasikmalaya berdasarkan Undang-Undang nomor 10 Tahun 2001 tentang Pembentukan Kota Tasikmalaya. Wilayah Kota Tasikmalaya meliputi bekas Wilayah Kota Administratif ditambah Kecamatan Indihiang, Kawalu, Mangkubumi, Cibeureum dan Tamansari. Saat ini Kota Tasikmalaya mempunyai 10 Kecamatan. Kecamatan Tawang sebagai salah satu kecamatan di Kota Tasikmalaya teridiri dari 5 kelurahan yaitu kelurahan tawang sari dengan jumlah $37 \mathrm{KK}$, kelurahan cikalang dengan jumlah $208 \mathrm{KK}$, kelurahan Lengkong sari dengan jumlah $271 \mathrm{KK}$, kelurahan kahuripan dengan jumlah $236 \mathrm{KK}$, dan kelurahan Empang sari dengan jumlah $43 \mathrm{KK}$. Total jumlah warga sebanyak 64.764 orang, dengan penduduk yang menerima bantuan PKH sebanyak $815 \mathrm{KK}$.

Masyarakat kelurahan lengkongsari telah dibekali ilmu mengenai cara pembuatan teh binahong dari program pengabdian kepada masyarakat. Beberapa manfaat dari tanaman binahong ini adalah dapat mengobati kerusakan ginjal, diabetes, pembengkakan jantung, muntah darah, tifus, stroke, wasir, rhematik, pemulihan pasca operasi, pemulihan pasca melahirkan, menyembuhkan segala luka-luka dalam dan khitanan, radang usus, melancarkan dan menormalkan peredaran dan tekanan darah, sembelit, sesak napas, sariawan berat, pusing-pusing, sakit perut, menurunkan panas tinggi, menyuburkan kandungan, maag, asam urat, keputihan, pembengkakan hati, meningkatkan, vitalitas dan daya tahan tubuh (Manoi, 2009), serta sebagai antioksidan (Selawa et al., 2013), antibiotik, antivirus, dan antiinflamasi (Kurniawan \& Aryan, 2015). Berdasarkan studi akut dan sub kronik yang dilakukan oleh Salasanti et al. (2014), ekstrak etanol daun binahong menunjukkan tidak adanya tanda-tanda toksik (beracun) atau ketidaknormalan sehingga aman untuk digunakan dalam pengobatan.

22 Edukasi Masyarakat Sehat Sejahtera (EMaSS) : Jurnal Pengabdian kepada Masyarakat Volume 2 No.1 Tahun 2020 
Adanya usaha yang didirikan ataupun sebagai wirausaha adalah salah satu jalan untuk menentukan kemajuan perekonomian. Karena dengan wirausaha maka seseorang akan mampu menciptakan lapangan kerja sendiri dan memberikan kesempatan bekerja untuk orang lain (Andari, 2011). Perilaku kewirausahaan dapat dibina dengan enam ciri utama yaitu percaya diri, berani mengambil resiko, berorientasi tugas hasil, kepimpinan, serta berorientasi ke masa depan untuk tercapainya tujuan (Hakim, 2007). Salah satu cara melakukan wirausaha adalah dengan sosial media. Sosial media merupakan konten yang berisi informasi yang sangat mudah diakses oleh berbagai pihak. Saat ini, praktek pemasaran melalui sosial media mulai berkembang dan digunakan sebagai alat pemasaran produk mempromosikan merek dan brand suatu perusahaan (Harjadi dkk, 2008).

Kurangnya pengetahuan masyarakat akan pengetahuan mengenai strategi kewirausahaan dan pemanfaatan aplikasi digital marketing dapat mengubur jiwa wirausaha dan tidak adanya tindak lanjut penjualan produk yang telah masyarakat lengkongsari miliki. Oleh karena itu, berdasarkan telaah permasalahan yang dihadapi mitra, maka kegiatan pengabdian masyarakat ini bertujuan memberikan pengetahuan/pelatihan kepada masyarakat tentang strategi kewirausahaan dan pemanfaatan aplikasi digital marketing agar masyarakat dapat berwirausaha dan memasarkan produk teh binahong ke masyarakat luas.

\section{METODE}

Kegiatan pengabdian ini dimulai dari bulan Juni-September 2019 di Kelurahan Lengkongsari, Kecamatan Tawang, Tasikmalaya, Jawa Barat (Gambar 1) dengan target utama ibu-ibu PKK sebanyak 8 orang.

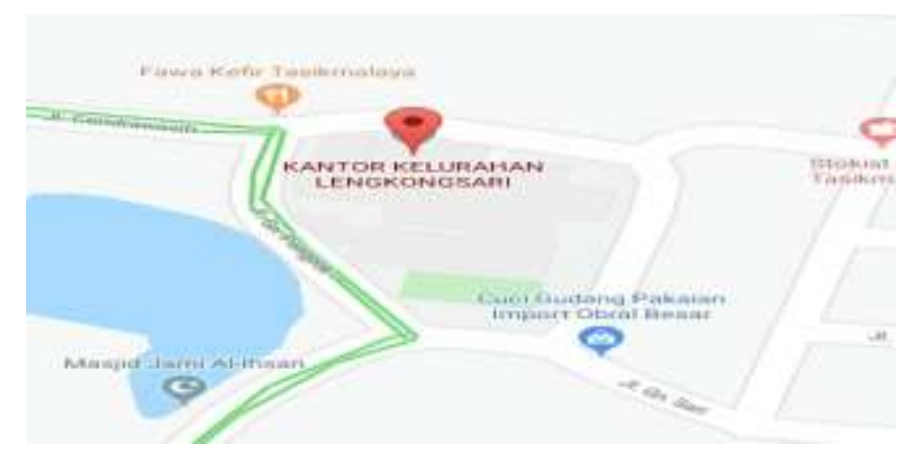

Gambar 1. Peta lokasi kegiatan PKM.

23 | Edukasi Masyarakat Sehat Sejahtera (EMaSS) : Jurnal Pengabdian kepada Masyarakat Volume 2 No.1 Tahun 2020 
Bahan yang digunakan meliputi daun binahong yang telah dikeringkan dan dihaluskan kemudian dikemas dengan kantong teh dan standing pouch. Alat yang digunakan adalah laptop untuk mengaplikasikan digital marketing.

Kegiatan pengabdian masyarakat dilaksanakan dalam tiga tahap yaitu persiapan, sosialisasi dan praktek lapangan. Tahap persiapan meliputi survey lokasi pelaksanaan kegiatan, mengurus perijinan pada Kantor Kelurahan, pembelian alat dan bahan, dan pendataan awal anggota PKK pada ketua PKK dan penentuan jadwal sosialisasi dan pelatihan. Kemudian dilanjutkan dengan tahap sosialisasi dalam bentuk ceramah/diskusi berupa penjelasan tentang strategi kewirausahaan, digital marketing serta cara pengemasan produk.

Pelatihan dimulai dengan melakukan sosialisasi mengenai strategi kewirausahaan dan digital marketing. Kemudian mengelompokkan target utama PKM (8 orang) menjadi tiga kelompok (2-3 orang/kelompok). Setiap kelompok didampingi tim PKM dan diberikan bahan dan alat penunjang yaitu laptop untuk melakukan strategi kewirausahaan melalui aplikasi digital marketing yaitu facebook. Secara umum, pembuatan teh binahong sudah dilakukan oleh masyarat, sehingga masyarakat hanya dibekali pengemasan teh binahong. Daun binahong yang sudah kering kemudian diambil tiga sendok untuk dimasukkan kedalam kantong serut teh celup. Kemasan sekunder menggunakan standing pouch. Masing-masing standing pouch terdiri dari 8 kantong teh.

\section{HASIL DAN PEMBAHASAN}

Pengabdian masyarakat dilakukan di Kelurahan Lengkongsari Kecamatan Tawang Kota Tasikmalaya. Proses pengabdian masyarakat dimulai dengan evaluasi produk teh binahong yang dilaksanakan pada tanggal 4 April 2019. Evaluasi berupa lembar kuesioner uji kesukaan warna, aroma, rasa dan tekstur teh binahong. Produk yang dievaluasi terdiri dari produk murni teh binahong original dan ditambahkan dengan gula. Responden berjumlah 10 orang dengan menggunakan skala likert.

Hasil uji hedonic dapat dilihat pada gambar 2 berikut ini:

24 | Edukasi Masyarakat Sehat Sejahtera (EMaSS) : Jurnal Pengabdian kepada Masyarakat Volume 2 No.1 Tahun 2020 


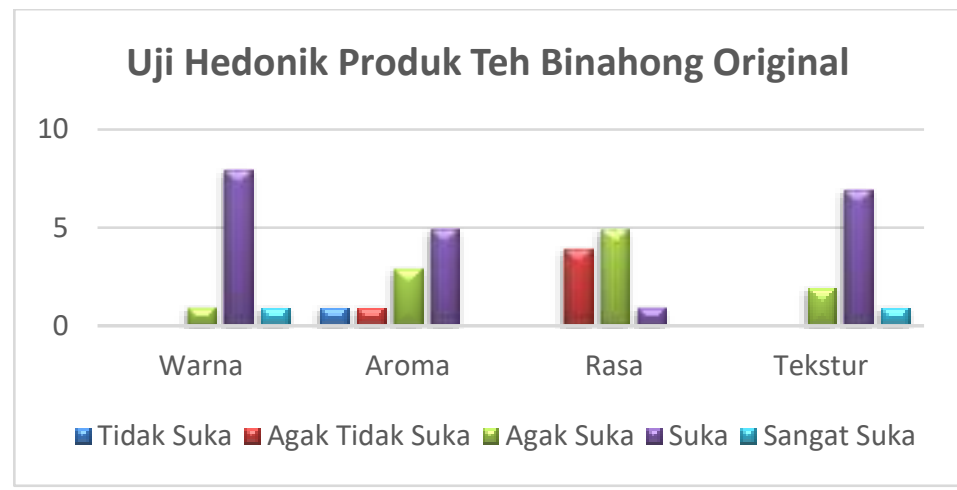

Gambar $2(\mathrm{~A})$

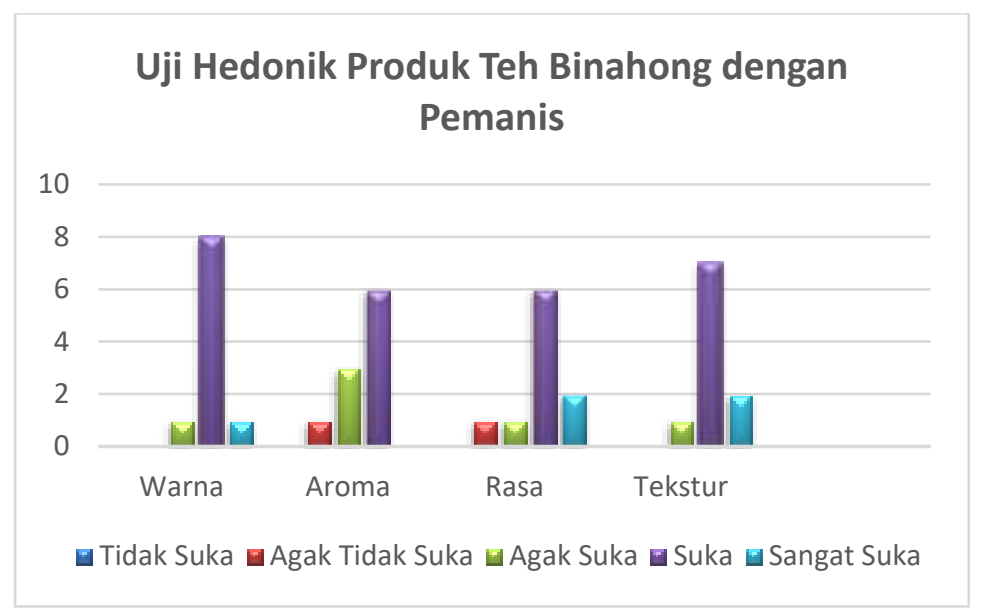

Gambar 2 (B)

Gambar 2. Grafik Uji Hedonik Produk (A) Teh Binahong Original

(B) Teh Manis Binahong

Produk yang diuji hedonic berupa produk original teh binahong dan teh binahong yang ditambahkan dengan gula. Berdasarkan gambar 5.1 dari 10 responden uji tes hedonic, dari segi warna baik produk original maupun ditambah gula memberi hasil yang sama yaitu $80 \%$ menyatakan menyukai warna. Namun dari segi aroma, responden lebih banyak menyukai teh manis binahong dengan persentase $60 \%$. Dari segi rasa terdapat perbedaan yang sangat signifikan. Teh original hanya disukai $10 \%$ dari total responden sedangkan teh manis berjumlah $60 \%$. Sedangkan dari segi tekstur sebesar $70 \%$ baik teh original ataupun teh manis memiliki persentase yang sama yaitu 70\%. Dari hasil uji hedonic ini dapat ditarik kesimpulan bahwa responden lebih banyak menyukai teh manis binahong. Namun dalam pembuatannya, teh binahong tersedia dalam 
rasa original. Dan apabila menyukai dengan penambahan gula maka dapat ditambahkan sesuai dengan selera.

Pada kegiatan selanjutnya dilakukan penyuluhan tentang kewirausahaan. Evaluasi awal berupa soal pre test untuk melihat tingkat pengetahuan awal peserta tentang kewirausahaan dan pemasaran. Kegiatan penyuluhan ini berupa bimbingan peningkatan pengetahuan tentang cara berwirausaha dan pemasaran. Pada kegiatan penyuluhan pemasaran disampaikan cara-cara berwirausaha dan cara memasarkan produk agar peserta pengabdian masyarakat memiliki motivasi untuk berwirausaha. Judul penyuluhan ini adalah "Strategi Kewirausahaan" yang dilaksanakan pada hari kamis tanggal 4 Juli 2019.

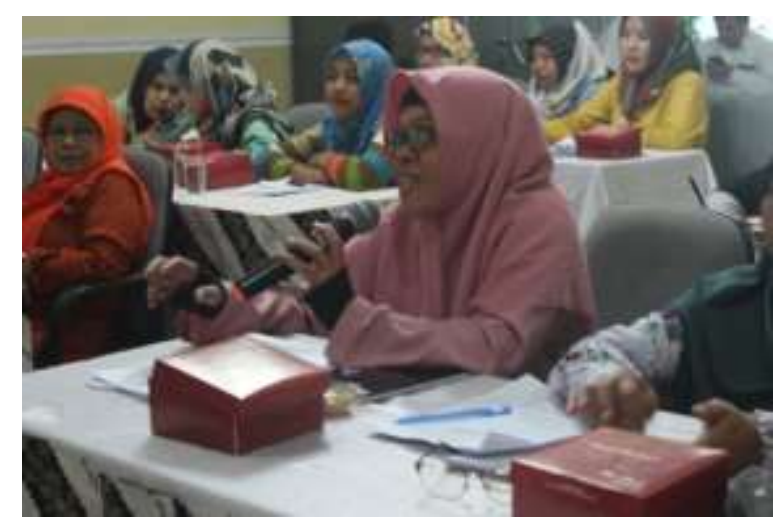

Gambar 3. Sosialisasi Strategi Kewirausahaan

Evaluasi yang dilakukan berupa pemberian ujian tulis di awal pelatihan (pre test) dan diakhir pelatihan (post test) kepada para peserta pelatihan, sehingga nantinya akan diketahui berapa besar pemahaman yang didapat oleh para peserta setelah melakukan pelatihan. Hasil penilaian memperlihatkan dari hasil nilai pretest dan postest terjadi peningkatan skor. Hal tersebut menunjukkan dari aspek pengetahuan terjadi peningkatan. Berikut ini adalah grafik hasil penilaian pre-test dan post-test materi strategi kewirausahaan dan digital marketing. 


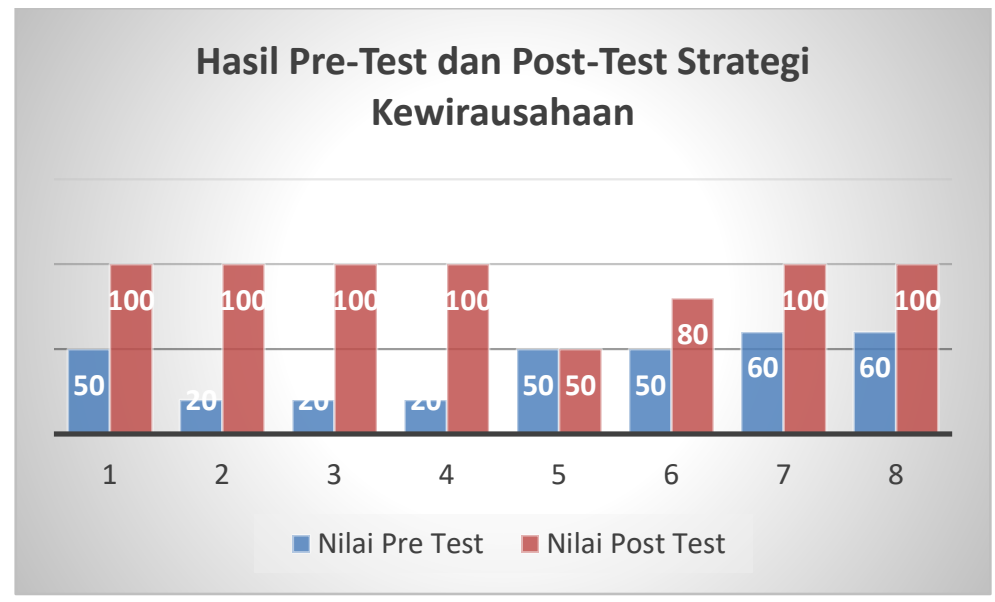

Gambar 4. Hasil pre-test dan post-test materi strategi kewirausahaan

Berdasarkan gambar 4 dengan jumlah responden 8 orang, terdapat peningkatan nilai pada 7 orang peserta atau sebesar $87,5 \%$. Peningkatan angka dari hasil tes tersebut dapat disebabkan oleh karena peserta yang merupakan ibu rumah tangga yang sangat antusias terhadap materi yang diberikan.

Pada kegiatan selanjutnya dilakukan penyuluhan dan workshop tentang pemasaran dan digital marketing. Kegiatan penyuluhan ini berupa bimbingan peningkatan pengetahuan tentang cara menggunakan facebook sebagai salah satu digital marketing. Pada kegiatan penyuluhan, pemateri menerangkan mengenai salah satu akun yang dapat digunakan untuk digital marketing, yaitu facebook. Kemudian setelah penyuluhan dilanjutkan dengan tahap workshop. Pada tahap workshop ini, masyarakat disediakan fasilitas laptop untuk dapat mengakses akun facebook yang dilaksanakan pada hari kamis tanggal 11 Juli 2019. Evaluasi yang dilakukan berupa adanya akun facebook dari masing-masing peserta workshop.

Tahap selanjutnya adalah tahapan evaluasi akhir setelah dilaksanakannya pengabdian kepada masyarakat ini. Evaluasi akhir ini merupakan follow up saat produk sudah dipasarkan pada akun facebook. Apakah ada tidaknya produsen yang tertarik untuk membeli produk teh binahong yang telah dipasarkan di akun facebook. Setelah diberikan waktu lebih kurang 2 bulan setelah diadakannya workshop, peserta diharuskan membuat produk the binahong dan dapat memasarkannya, kemudian dilakukan proses evaluasi untuk melihat progress penjualan. Berikut adalah grafik evaluasi penjualan teh binahong.

27 | Edukasi Masyarakat Sehat Sejahtera (EMaSS) : Jurnal Pengabdian kepada Masyarakat Volume 2 No.1 Tahun 2020 


\section{Keterangan:}

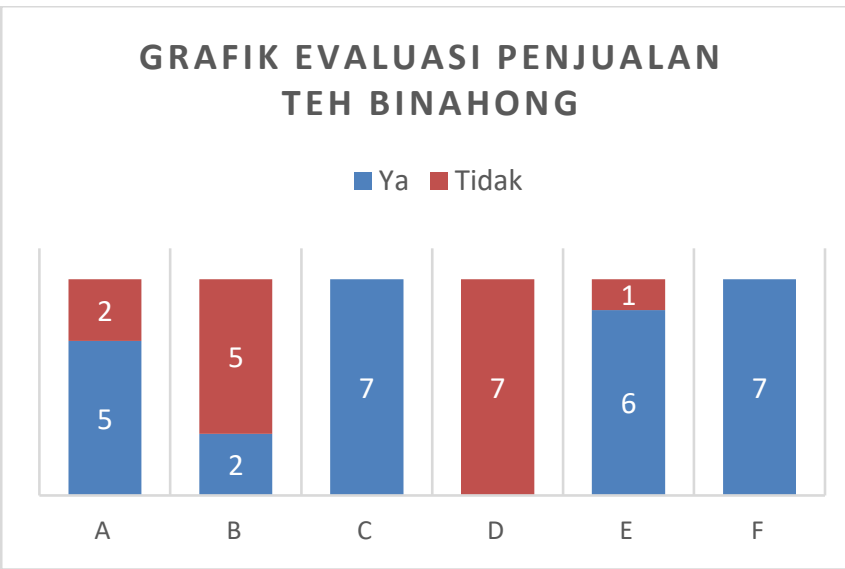

Gambar 5 Grafik Evaluasi Penjualan teh Binahong
A : Pengetahuan Akun Facebook
B : Pengetahuan Pemasaran Produk Umum
C : Pengetahuan Pengolahan Produk Teh Binahong
D : Pengetahuan Pemasaran Produk pada Facebook
E : Peminat Produsen untuk Membeli Produk
F : Peminat Menjual Produk Skala Besar

Berdasarkan gambar 5 dari 7 orang responden menyatakan 5 responden mengetahui mengenai akun facebook atau sebesar 71,4\%. Sedangkan pengetahuan mengenai cara pemasaran produk secara umum sebesar $28,6 \%$. Seluruh responden sudah mengetahui cara pengolahan produk. Namun tidak ada satupun yang telah menjual dalam akun facebook. Sebesar $85,7 \%$ sudah banyak pembeli yang berniat ingin membeli produk teh binahong. Dan seluruh peserta berminat untuk menjadi penjual dalam skala besar. Tidak adanya penjualan di facebook ini dikarenakan tidak adanya tanaman binahong di daerah yang telah ditanam binahong karena terdapat miss communication dengan pemimpin RT setempat dan pendeknya deadline waktu yang diberikan. Meskipun telah dilakukan proses evaluasi, namun proses produksi dan penjualan tetap dilakukan.

\section{SIMPULAN}

Kegiatan pengabdian kepada masyarakat di Kelurahan Lengkongsari, Tasikmalaya berfokus pada sosialisasi dan aplikasi pelatihan digital marketing. Pelatihan ini telah memberi dampak positif terhadap masyarakat, yaitu pengetahuan mitra tentang cara pengemasan teh binahong, strategi kewirausahaan dan aplikasi digital marketing meningkat, masyarakat antusias menggunakan aplikasi digital unutk proses pemasaran teh binahong, dan antusias menerima pengetahuan dan skill yang terlihat dari peningkatan pengetahuan post-test. Manfaat positif lain 
yang diperoleh dari penjualan teh binahing adalah dapat dijadikan sarana penyaluran hobi, kesehatan, dan dapat dikembangkan menjadi skala bisnis yang menjanjikan.

\section{UCAPAN TERIMA KASIH}

Ucapan terima kasih kepada Poltekkes Kemenkes Tasikmalaya atas hibah yang diberikan melalui program Pengabdian Kepada Masyarakat pada tahun 2019, sehingga kegiatan ini dapat berjalan dengan baik dan lancar. Ucapan terima kasih juga kepada UPPM Poltekkes Kemenkes Tasikmalaya serta perangkat Keluarahan Lengkongsari atas dukungan teknis, fasilitas, administrasi untuk kelancaran pengabdian kepada masyarakat.

\section{DAFTAR PUSTAKA}

Andari Ressa. (2011). Pengaruh Kompetensi Pengusaha Kompetensi Pengusaha, Bandung: Universitas Pendidikan Indonesia.

Hakim Arman Nasution. (2007). Entrepreneurship, Membangun Spirit Teknonopreneurship. Yogyakarta.

Harjadi, Didik \& Fatmawati Dewi. (2008). Word Of Marketing (WOM) Communication Sebagai Alternatif Kreatif Dalam Komunikasi Pemasaran. JURNAL EQUILIBRIUM. Vol.4, No.8, Juli-Desember 2008; 72-78.

Kurniawan, B., \& W. F. Aryana. (2015). Binahong (Cassia alata L) as Inhibitor Eschericia coli Growth, J Majority, 4(4) : $100-104$

Manoi, F. (2009). Binahong (Anredera cordifolia) Sebagai Obat. Warta Penelitian dan Pengembangan Tanaman Industri, 15(1): $3-5$.

Salasanti, C. D., E. Y. Sukandar, I. Fidrianny.( 2014). Acute and SubChronic Toxicity Study of Ethanol Extract of Anredera cordifolia (Ten.) Steenis Leaves. International Journal of Pharmacy and Pharmaceutical Sciences , 6(5) : 348 -352.

Selawa, W., M. R. J. Runtuwene, \& G. Citraningtyas. (2013). Kandungan Flavonoid dan Kapasitas Antioksidan Total Ekstrak Etanol Daun Binahong (Anredera cordifolia(Ten.) Steenis). Pharmacon Jurnal Ilmiah Farmasi Unsrat, 2(1) : 18 -22

29 | Edukasi Masyarakat Sehat Sejahtera (EMaSS) : Jurnal Pengabdian kepada Masyarakat Volume 2 No.1 Tahun 2020 